\title{
Meeting Report: The XXVth Slovak-Czech Conference on Hemostasis and Thrombosis (with International Participation), Martin, Slovak Republic
}

\author{
Lucia Stanciakova, MD, $\mathrm{PhD}^{1}$ Peter Kubisz, MD, $\mathrm{DSc}^{1}$ Jan Stasko, MD, $\mathrm{PhD}^{1}$ Jaroslav Maly, MD, $\mathrm{PhD}^{2}$ \\ ${ }^{1}$ Department of Hematology and Transfusion Medicine, National \\ Center of Hemostasis and Thrombosis, Martin University Hospital, \\ Jessenius Faculty of Medicine in Martin, Comenius University in \\ Bratislava, Martin, Slovak Republic \\ ${ }^{2}$ Department of the Internal Medicine IV - Hematology, Faculty of \\ Medicine in Hradec Kralove, Charles University in Prague, Prague, \\ Address for correspondence Lucia Stanciakova, MD, PhD, \\ Department of Hematology and Transfusion Medicine, National \\ Center of Hemostasis and Thrombosis, Martin University Hospital, \\ Jessenius Faculty of Medicine in Martin, Comenius University in \\ Bratislava, 03659 Martin, Slovak Republic \\ (e-mail: stanciakova@jfmed.uniba.sk).
} Czech Republic

Semin Thromb Hemost 2019;45:117-120.

The XXVth Slovak-Czech Conference on Hemostasis and Thrombosis (with international participation) was held in May 24 to 26, 2018, at the Hotel Victoria in Martin-a most typical Slovak city and a cultural center of Slovakia. The conference, reflecting the mutual understanding of two neighboring nations, Slovakia and Czech Republic, with common interests in the field of hemostasis and thrombosis, was jointly organized by the Slovak Society on Hemostasis and Thrombosis of the Slovak Medical Society, and the Czech Society on Thrombosis and Hemostasis of the Czech Medical Society of Jan Evangelista Purkyně. The conference takes place each year, and the location alternates between Slovakia and Hradec Kralove in the Czech Republic, with the main input from Professor Jaroslav Maly, MD, PhD, and Associate Professor Petr Dulicek, MD, PhD, as organizing members of the Scientific Committee. In general, the conference's aim is to summarize current knowledge and future trends of research within the field of hemostasis and thrombosis in both countries-Slovakia and Czech Republic-via a series of invited and submitted presentations. The expectation is that the conference will continue to progress understanding of hemostasis and thrombosis and the strong mutual cooperation and ties of these countries.

The main topics of the conference for this year were the physiology and pathophysiology of hemostasis, inherited and acquired thrombophilia, inherited and acquired bleeding disorders-hemophilia, inhibitors and immune tolerance induction (ITI), inherited disorders of fibrinogen, von Willebrand disease and rare bleeding disorders, lifethreatening bleeding, coagulation factors, prophylaxis and treatment of thromboembolism in the era of direct oral anticoagulants (DOACs), malignant diseases and hemostasis, updates in laboratory diagnostics of disorders of hemostasis and its monitoring, as well as hemostasis as related to other clinical fields of medicine-including angiology, vascular surgery, cardiology, neurology, gynecology and obstetrics, pediatrics, orthopedics, anesthetics, and intensive care medicine.

Prestigious guests from all over the world also came to the meeting. Altogether, 73 lectures including the honorable Jessenius lecture, postgraduate presentations, educational satellite symposia, and brainstorming of postgraduate students of the Jessenius Faculty of Medicine in Martin. Over 300 participants attended the conference, and 16 poster presentations were exhibited.

\section{Day 1}

The sessions comprised acquired hemophilia, hemophilia with inhibitors and ITI, DOACs, platelets, and rare inherited bleeding disorders.

The need for careful differential diagnosis allowing successful subsequent management of patients was highlighted in various aspects of bleeding disorders. Hematologists from the largest centers of hemostasis from Slovakia and Czech Republic-Peter Salaj, MD (Prague, Czech Republic), Erika Cellarova, MD (Banská Bystrica, Slovak Republic), Associate Professor Maria Hulikova, MD, PhD and Lucia Cabinakova, MD (both from Košice, Slovak Republic), and Ivana Plamenova, MD, PhD and Lucia Stanciakova, MD, PhD (both from Martin, Slovak Republic)-reported their experiences with the treatment of acquired hemophilia, inhibitory antibodies in inherited hemophilia, as well as the advances in the treatment of rare bleeding disorders. published online December 19, 2018
Issue Theme Editorial Compilation VI; Guest Editors: Emmanuel J. Favaloro, PhD, FFSc (RCPA), and Giuseppe Lippi, MD.
Copyright $\odot 2019$ by Thieme Medical Publishers, Inc., 333 Seventh Avenue, New York, NY 10001, USA. Tel: +1(212) 584-4662.
DOI https://doi.org/ 10.1055/s-0038-1676316. ISSN 0094-6176. 
Another hallmark of the meeting, and highly appreciated by the auditorium audience, was the session dedicated to recent advances in the use of DOACs in various clinical situations. The first lecture was delivered by Professor Emmanuel J. Favaloro, BSc (Hons), MAIMS, PhD, FFSc (RCPA) (Sydney, Australia), who presented a cross-sectional review of anticoagulant treatment from the Australian perspective, but which was likely mirrored within other locations.

Subsequent speakers raised questions regarding concomitant treatment of DOACs with proton pump inhibitors or their monitoring/measurement in specific clinical situations from the point of view of hematologists and cardiologists.

Postgraduate students of the Jessenius Faculty of Medicine in Martin were also given the opportunity to introduce their dissertation topics.

The Opening Ceremony, held in the National House, Slovak Chamber Theater, marked the close of the first day of the conference. The Opening Ceremony was initiated by a speech of the President of the Slovak Society on Hemostasis and Thrombosis, Professor Peter Kubisz, MD, DSc, the CoPresident of the Conference, Professor Jaroslav Maly, MD, $\mathrm{PhD}$, the President of the Czech Society on Thrombosis and
Hemostasis of the Czech Medical Society of Jan Evangelista Purkyně, Professor Jan Kvasnicka, MD, DSc, the Dean of the Jessenius Faculty of Medicine in Martin, Comenius University in Bratislava, Professor Jan Danko, MD, CSc, and the General Director of the Martin University Hospital, Dusan Krkoska, $\mathrm{MD}, \mathrm{PhD}, \mathrm{MBA}$. Special attention was paid to the awarding of foreign guests of the conference-Professor Emmanuel J. Favaloro, BSc (Hons), MAIMS, PhD, FFSc (RCPA), Professor Guillermo J. Ruiz-Arguelles, MD, FRCP (Glasg), MACP, DSc (hc), Professor Rosanna Asselta, PhD, and Alessandro Casini, MD. After the official part of the ceremony, the attendees (-Figs. 1 and 2) had the opportunity to see an unusual performance of the group Fragile singing in a cappella style.

\section{Day 2}

Sessions of this day comprised news in hemophilia treatment, thrombophilia, the keynote Jessenius lecture, clotting factor concentrates, sticky platelet syndrome (SPS) - paradigm shift, von Willebrand disease and von Willebrand factor, inherited fibrinogen disorders, and heparin-induced thrombocytopenia.

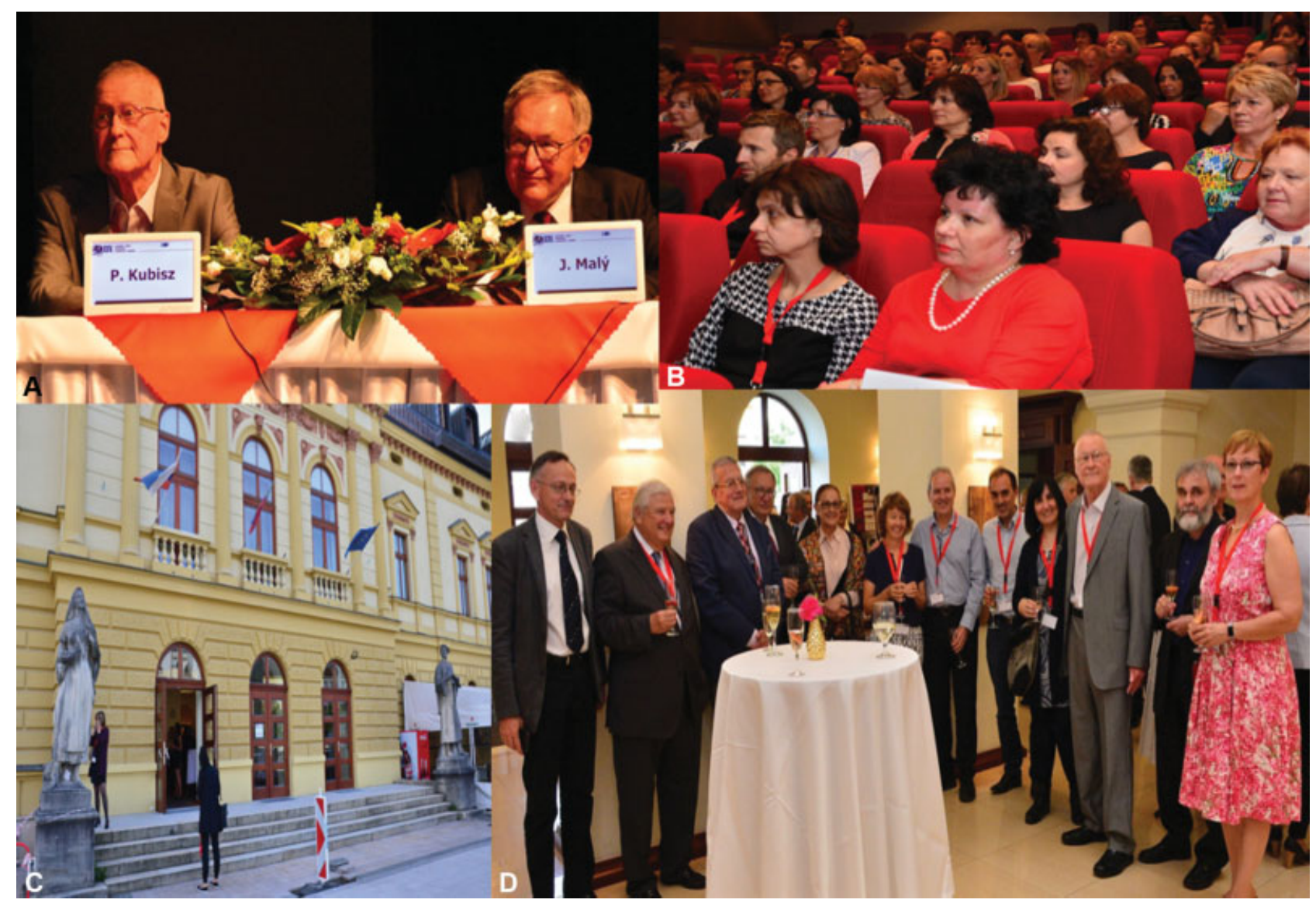

Fig. 1 Some memorable moments of the meeting Part I. (A) Presidents of the conference-Professor Peter Kubisz, MD, DSc, and Professor Jaroslav Maly, MD, PhD, (B) auditorium of the event, (C) venue of the opening ceremony - National House, Slovak Chamber Theater, and (D) foreign guests with Members of the Organizational Committee-from the left Professor Jan Stasko, MD, PhD, Professor Jan Kvasnicka, MD, DSc, Guillermo J. Ruiz-Arguelles, MD, FRCP (Glasg), MACP, Professor Jaroslav Maly, MD, PhD, Mrs. Ruiz-Arguelles, Mrs. Favaloro, Professor Emmanuel J. Favaloro, BSc (Hons), MAIMS, PhD, FFSc (RCPA), Alessandro Casini, MD, Professor Rosanna Asselta, PhD, Professor Peter Kubisz, MD, DSc, Petr Kessler, MD, and Lubica Rauova, MD, PhD. 


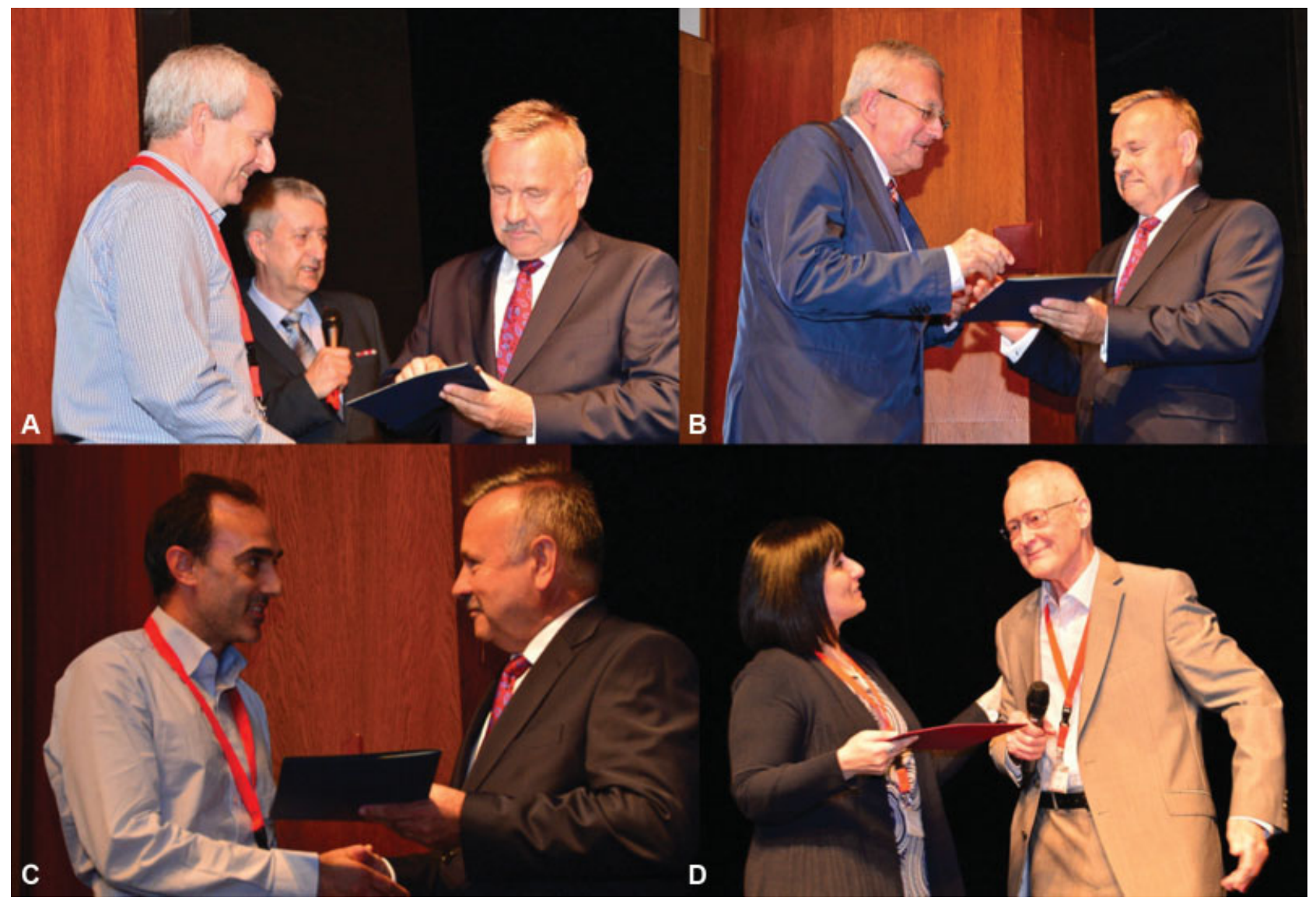

Fig. 2 Some memorable moments of the meeting Part II. Some honors were given to the foreign guests during the opening ceremony: (A) Professor Emmanuel J. Favaloro, BSc (Hons), MAIMS, PhD, FFSc (RCPA) awarded by Professor Jan Danko, MD, PhD (in the back, there is the organizer Igor Vico, MD), (B) Guillermo J. Ruiz-Arguelles, MD, FRCP (Glasg), MACP, and Professor Jan Danko, MD, PhD, (C) Professor Jan Danko, MD, PhD gives an award to Alessandro Casini, MD, and (D) Professor Rosanna Asselta, PhD awarded by Professor Peter Kubisz, MD, DSc.

Novel therapeutic possibilities in the treatment of hemophilia were introduced by an expert in this field of study, Professor Paul L.F. Giangrande, BSc, MD, FRCP (Lond., Edin., \& Ireland), FRCPath, FRCPCH (Oxford, United Kingdom).

Another outstanding segment of the day was the honorable Jessenius lecture, on diagnostics of von Willebrand disease, delivered by one of the world's most recognized experts in the field of laboratory testing and diagnostics of bleeding and thrombotic disorders-Professor Emmanuel J. Favaloro, BSc (Hons), MAIMS, PhD, FFSc (RCPA) (Sydney, Australia).

Jan Jessenius was born on December 27, 1566, and was a physician-surgeon, anatomist, humanistic educator, philosopher, occasional poet, and politician whose father was born in Turcianske Jaseno near Martin, Slovak Republic. In the years 1597 to 1600, Jan Jessenius worked as the Rector of the University in Wittenberg and later also as the Rector of the Charles University in Prague (1617-1620). He is perhaps most famous for the performance of the first public autopsy in Prague in 1600. Last but not least, he was interested in the description of the color, composition, and process of blood clotting. Due to the importance of his advances in the field of medicine, the Faculty of Medicine in Martin takes his name and during each year of this particular conference held in Martin (each even-numbered year), the most honorable lecture is also named after him.
Statistics regarding consumption and possibilities around providing clotting factor concentrates for patients with bleeding disorders were the subject of the next session entitled "Clotting factor concentrates," as provided by Dr. Lubica Hlinkova, PhD, MPH (Bratislava, Slovak Republic).

The subsequent session on SPS was also of considerable interest for the audience, as documented by the subsequent vigorous discussion. One of the presidents of the conference, Professor Peter Kubisz, MD, DSc (Martin, Slovak Republic) dedicated the presentation to the history of the platelet hyperaggregability syndrome.

The treatment of individuals diagnosed with SPS, particularly when coincident with other thrombophilia markers, may be problematic and require combinations of antithrombotic drugs-usually the use of vitamin $\mathrm{K}$ antagonists or low-molecular-weight heparin with antiplatelet drugs (usually aspirin and occasionally clopidogrel). Unfortunately, there are still no universal guidelines, and treatment should be individualized to the patient. However, therapy is still often accompanied by complications associated with adverse events of medication (particularly bleeding) or thrombosis recurrence. ${ }^{1}$ Therefore, this challenging issue, namely, diagnostics and treatment of SPS, was presented to the audience by Pavol Holly, MD, PhD (Martin, Slovak Republic), who works for the National Center of 
Hemostasis and Thrombosis in Martin and has extensive experience with such complicated treatment.

In the subsequent course of the session, the epidemiology and etiopathogenesis of the syndrome including its genetics were introduced. Moreover, specific management of pregnant patients with SPS and management of SPS in Mexico were presented by Guillermo J. Ruiz-Arguelles, MD, FRCP (Glasg), MACP (Puebla, Mexico).

Other highlights of the day were the presentations of Professor Rosanna Asselta, PhD (Milan, Italy) and Alessandro Casini, MD (Geneva, Switzerland) linking the genotype with the prediction of prognosis and clinical phenotype of the patients with inherited bleeding disorders, and the invited lecture of Lubica Rauova, MD, PhD (Baltimore, MD) on heparin-induced thrombocytopenia.

Besides the lectures, the poster session with presentations in printed or electronic forms was also prepared. Conference highlights and the willingness to network and share experiences allowed the continuation of discussions over the evening gala dinner. At this occasion, the authors of the best posterJana Bilkova, MA (Prague, Czech Republic), Jana Prochazkova, MD (Olomouc, Czech Republic), and Maria Skerenova, MSc, PhD (Martin, Slovak Republic)-were awarded.

\section{Day 3}

Sessions for this day were anesthesiology and intensive care, vascular medicine, and cardiology-this being supported by the Agency for Research and Development.

These sessions focused on the multidisciplinary approach to hemostasis. Professor Beata Drobna-Saniova, MD, PhD (Martin, Slovak Republic) provided a useful review of the recent European guidelines of perioperative prophylaxis of venous thromboembolism. Also valuable were subsequent lectures that informed on the treatment of life-threatening bleeding and treatments with newly modified activated recombinant coagulation factor VII.

Hematologists researchers from the Department of Internal Medicine I (Matej Samos, MD, PhD, and Tomas Bolek, MD) and from the Department of Hematology and Transfusion Medicine (Radoslava Simonova, MD, PhD) introduced the audience to their contribution to clinical practice by the implementation of results of projects related to monitoring the effectiveness of antiplatelet therapy in the patients with acute coronary syndrome and their everyday management.

The session related to vascular medicine reviewed pharmacological options of anticoagulant treatment for chronic thrombosis, secondary thromboprophylaxis in patients with past history of venous thromboembolism, and the problematics of the postthrombotic syndrome.

During the closing ceremony, the presidents of the conference summarized the meeting and expressed their wish to continue the tradition of these Slovak-Czech meetings also in the future, by a general invitation to attend the XXVIth Czech-Slovak Conference on Thrombosis and Hemostasis in Hradec Králové, Czech Republic, planned to be held in May 2019.

We would like to thank all of the active participants of the meeting for their efforts to expand our scientific horizons and all the attendees for their participation and attention. We cordially hope that the attendance at the event was beneficial for all, especially considering the high-quality lectures, the possibility to share their clinical experience with other hematologists, and finally that the meeting provided inspiration for further scientific work.

\section{References}

1 Kubisz P, Stasko J, Holly P. Sticky platelet syndrome. Semin Thromb Hemost 2013;39(06):674-683 